\title{
Relevant Frequency of Multiple Infections with High- and Low-Risk HPV Genotypes among Mexican Women Attending a Tertiary Care Hospital
}

\author{
Saúl Flores-Medina ${ }^{1,2,3 *}$, Carmen S. García-Romero4, Diana M. Soriano-Becerril4, \\ Francisco J. Díaz-García ${ }^{5}$, Silvia Giono-Cerezo6, Graciela Castro-Escarpulli ${ }^{6}$ \\ ${ }^{1}$ Departamento Editorial, Instituto Nacional de Perinatología, Ciudad de México, México \\ ${ }^{2}$ CECyT No. 15 “DAE”, Instituto Politécnico Nacional, Ciudad de México, México \\ ${ }^{3}$ Programa de Biología y Biotecnología Molecular, Escuela Nacional de Ciencias Biológicas, Instituto Politécnico \\ Nacional, Ciudad de México, México \\ ${ }^{4}$ Departamento de Infectología, Instituto Nacional de Perinatología, Ciudad de México, México \\ ${ }^{5}$ Departamento de Biología, Facultad de Química, Universidad Nacional Autónoma de México, Ciudad de \\ México, México \\ ${ }^{6}$ Laboratorio de Bacteriología Médica, Departamento de Microbiología, Escuela Nacional de Ciencias \\ Biológicas, Instituto Politécnico Nacional, Ciudad de México, México

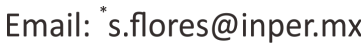

Received 17 May 2016; accepted 14 June 2016; published 17 June 2016

Copyright (C) 2016 by authors and Scientific Research Publishing Inc.

This work is licensed under the Creative Commons Attribution International License (CC BY). http://creativecommons.org/licenses/by/4.0/

(c) (i) Open Access

\section{Abstract}

Aims: To assess the frequency and the main HPV genotypes circulating among a group of women attending at a third level Hospital in Mexico City. Methods: A cross-sectional and descriptive study was performed in a group of 143 female outpatients of the Gynecology and Obstetrics Service at the National Institute of Perinatology of Mexico. Cervical swabs were taken from participants and subjected to simultaneous detection/genotyping of HPV by Linear Array Genotyping Test (Roche Molecular Systems). Mann-Whitney U, median and/or Square Chi tests were used to compare socio-demographical features between HPV-infected and uninfected women. Results: A total of 66 women (46.2\%) had HPV infection. Overall, 112 genotypes were detected either as single infections (45.5\%) or multiple genotype infections (54.5\%). The cumulated frequency of multiple infections with high-/low- and high-/high-risk HPV genotypes was $63.9 \%$. The most frequent high-risk genotypes were HPV52 HPV58 and HPV51, whereas the most frequent low-risk genotypes were HPV6, HPV53 and HPV84. Infected women were significantly younger and have less stable partner relationships than uninfected women $(p<0.05)$. Conclusion: $A$ relevant frequency of mixed infections with high- and low-risk HPV genotypes, other than those consi-

\footnotetext{
${ }^{*}$ Corresponding author.
}

How to cite this paper: Flores-Medina, S., García-Romero, C.S., Soriano-Becerril, D.M., Díaz-García, F.J., Giono-Cerezo, S. and Castro-Escarpulli, G. (2016) Relevant Frequency of Multiple Infections with High- and Low-Risk HPV Genotypes among Mexican Women Attending a Tertiary Care Hospital. Open Journal of Obstetrics and Gynecology, 6, 424-432. 
dered most prevalent worldwide, was observed. Most circulating high-risk genotypes among the women of this study are not covered by commercial vaccine formulations.

\author{
Keywords
}

Human Papillomavirus, High-Risk Genotypes, HPV Co-Infections, Linear Array Genotyping

\title{
1. Introduction
}

Strong association between female genital infection with any of the 15 recognized high-risk HPV genotypes and development of cervical cancer has been well established [1]-[3]. Besides high-risk HPV infection, other factors such as promiscuity, weak immune responsiveness, genetic background, long term tobacco smoking and use of oral contraceptives influence malignant transformation [3] [4]. Low-risk HPV genotypes are more commonly associated with warts and low-grade squamous intraepithelial lesions (LSIL) [2] [5].

A latent or persistent infection caused by several HPV genotypes is more likely to occur during pregnancy, even with no evidence of clinical signs. Estimations indicate that less than 10\% of HPV-infected women will suffer life-long persistent infection [6].

Since a high proportion of HPV infection is subclinical, cytological and histo-pathological examinations are of restricted clinical value. Use of improved and faster detection/typing methods of HPV in the clinical settings, has allowed identification of women with mild lesions which are prone to evolve into high-grade lesions or carcinomas [6]-[9].

After suspicion of HPV infection, secondary to the main gynecological-obstetric condition of patients, intervention measures at the Mexico's National Institute of Perinatology are restricted to confirmation by colposcopy and/or histo-cytologic examinations. If required, patients are referred to specialized oncologic health services [10].

Considering the above mentioned, the aim of this study was to assess the frequency of HPV genital infection among women with antecedents of HPV infection but without cervical lesions, as well as to identify the circulating HPV genotypes among that group of women at the National Institute of Perinatology in Mexico City.

\section{Material and Methods}

\subsection{Patients}

This was a cross-sectional and descriptive study of HPV infection among a group of 145 women without colposcopic evidence of cervical lesions, aged 15 to 68 years. The study was carried out between January and December 2012. Participants were non-randomly selected on convenience basis according to clinical criteria for past or suspected HPV infection, at the National Institute of Perinatology in Mexico City. All women sought primarily gynecologic/obstetric care. The study was approved by the Institutional Research and Ethics Committee (Protocol no. 212250-22761). Informed consent was obtained from all individual participants.

\subsection{Samples}

Cervical specimens were retrieved by thorough swabbing of the exo- and endo-cervix regions, and collected into PreservCyt ${ }^{\mathrm{TM}}$ transport solution-containing vials (Marlborough, Mass., USA). Cervical specimens were kept frozen at $-20^{\circ} \mathrm{C}$ until processing. Simultaneously, each patient was asked to answer a clinical and socio-demographical questionnaire.

\subsection{HPV Genotyping}

We used the qualitative "Linear Array HPV Genotyping Test" (Roche Molecular Systems Inc., Branchburg, NJ), according to manufacturer's instructions. This test is designed for specific simultaneous detection and typing of up to $37 \mathrm{HPV}$ genotypes usually found in the human anogenital region, including 13 and 24 of the most frequent 
high- and low-risk genotypes, respectively.

Total DNA was extracted from each specimen by treatment with a proteinase K-containing alkaline lysis buffer, and immediately purified by spin sepharose column chromatography. (Qiagen GmbH, Hilden, Germany). Ten-microliter aliquots of the purified DNA samples were subjected to PCR amplification in a $100 \mathrm{uL}$ volume of reaction mix containing $50 \mu \mathrm{L}$ of $2 \mathrm{X}$ master mix, $40 \mu \mathrm{L}$ of deionized water, and two primers sets, one specific for the HPV L1 gene and the other specific for the human $\beta$-globin gene (as quality control of purified DNAs). Amplification was started by incubation at $50^{\circ} \mathrm{C} / 2 \mathrm{~min}$ and denaturation at $95^{\circ} \mathrm{C} / 9 \mathrm{~min}$, followed by 40 cycles of denaturation at $95^{\circ} \mathrm{C} / 30 \mathrm{~s}$-annealing at $55^{\circ} \mathrm{C} / 1 \mathrm{~min}$ - extension at $72^{\circ} \mathrm{C} / 1 \mathrm{~min}$, and a final extension at $72^{\circ} \mathrm{C} / 10$ min. Positive and negative controls were included in each assay run. After amplification, samples were chemically denatured and poured individually onto cellulose strips with separately blotted recombinant DNA sequences from $37 \mathrm{HPV}$ genotypes. Hybridization was detected by a colorimetric technique directly onto the strips.

\subsection{Data Analysis}

Socio-demographical and/or frequencies of genotypes data from HPV-infected and uninfected women were statistically compared by using the SPSS v.20 for Windows (IBM, New York, USA). Continuous data were analyzed through Mann-Whitney U or median tests, while analyses of proportions were done by square chi tests.

\section{Results}

One hundred and forty three cervical specimens gave valid results in the Linear Array HPV Genotyping Test, while two specimens failed to amplify internal control ( $\beta$-globin gene) and thus were ruled out from further analysis. At least one HPV genotype was detected in 66 specimens (46.2\%), while no HPV DNA was detected in $77(53.8 \%)$.

Analyses of the socio-demographic features revealed that HPV-infected women were significantly younger ( $p$ $=0.012)$ and apparently spent fewer years for education than women without HPV infection $(p=0.058$, Table 1). In addition, a higher proportion of women without HPV infection seem to have long term partner relationships than infected women $(p=0.015)$. The number of sex partners and the age at which women became sexually active did not differ considerably between HPV-infected and uninfected subgroups.

The comparison of socio-demographic features between single- and multiple-genotype HPV-infected women revealed no significant differences (Table 2), even though women in the latter group had slightly more sex partners.

Regarding detection/genotyping, a total of 112 positive HPV signals were obtained among the study group, corresponding to 28 out of the 37 detectable genotypes by the test used here. Approximately one third of all viruses detected were identified as high-risk HPV genotypes, whereas the remaining viruses were identified as low-risk genotypes, whose individual frequencies are shown in Figure 1. Overall, the most frequent genotypes among study group were HPV6, 52, 53 and 58.

Figure 2 shows multiple-genotype infections (with up to four genotypes) in single samples. Noteworthy these multiple-genotype infections were slightly more frequent than single-genotype infections $(54.5 \%$ vs. $45.5 \%$, respectively). Interestingly the two-genotype HPV infections were the more frequent form of multiple-genotype infection, either of the same oncogenic risk category or of combined risk categories (Table 3 ).

The low-risk HPV6 was the predominant genotype among patients with single-genotype infection, followed by low-risk HPV53 and high-risk HPV16. The approximate ratio of low-risk to high-risk genotypes among the single-genotype infected women was 2:1 (Table 3). The predominant combination of multiple HPV genotype infection was that of HPV52 plus HPV58 genotypes, reaching 13.9\% (Table 3).

\section{Discussion}

Rise in worldwide HPV prevalence among women, and consequently a rise in cases of cervical cancer (from 378,000 cases per year in 1980 to 454,000 cases per year in 2010), has been observed in the past 2 decades, although it varies geographically, and according to age and other factors [11]-[15].

On one hand, it is undeniable that ultimate generation DNA extraction/purification and amplification methods have had an enormous impact on improving detection of infectious agents in the clinical setting. On the other 


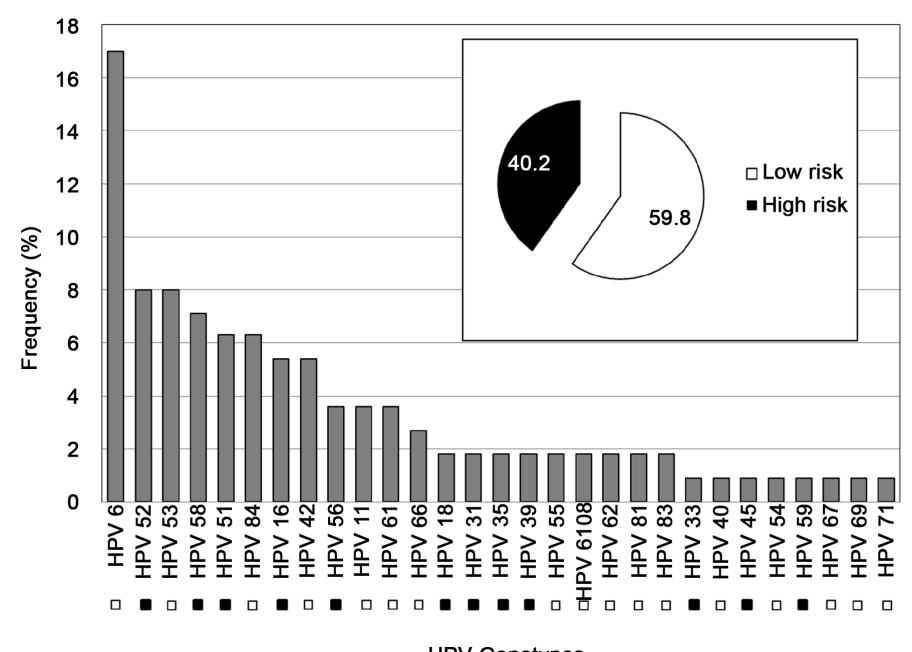

HPV Genotypes

Figure 1. Oncogenic risk and frequencies of HPV genotypes.

Table 1. Socio-demographic features of women in this study.

\begin{tabular}{|c|c|c|c|}
\hline \multirow{2}{*}{ Variable } & \multicolumn{3}{|c|}{ HPV status } \\
\hline & Infected $n=66$ & Non Infected $\mathbf{n}=77$ & p value ${ }^{\dagger}$ \\
\hline \multicolumn{4}{|l|}{ Age (years) } \\
\hline Mean \pm SD (Standard Deviation) & $28.6 \pm 9.0$ & $33.7 \pm 10.1$ & $0.012^{\star}$ \\
\hline Median & 26.5 & 31.0 & \multirow{3}{*}{$\begin{array}{c}\mathrm{NS}^{\S} \\
0.027^{\Uparrow}\end{array}$} \\
\hline$\leq 21$, No. $(\%)$ & $16(24.2)$ & $8(10.4)$ & \\
\hline$>21$, No. $(\%)$ & $50(75.8)$ & $69(89.6)$ & \\
\hline \multicolumn{4}{|l|}{ Age at first sexual Intercourse (years) } \\
\hline Mean \pm SD & $19.2 \pm 4.6$ & $19.4 \pm 4.2$ & $\mathrm{NS}^{\ddagger}$ \\
\hline Median & 18.0 & 19.0 & $\mathrm{NS}^{\S}$ \\
\hline$\leq 16$, No. $(\%)$ & $23(34.8)$ & $17(22.1)$ & \multirow{2}{*}{$\mathrm{NS}^{\pi}$} \\
\hline$>16$, No. $(\%)$ & $43(65.2)$ & $60(77.9)$ & \\
\hline \multicolumn{4}{|l|}{ Number of sex Partners } \\
\hline Mean \pm SD & $3.5 \pm 4.1$ & $2.7 \pm 2.2$ & $\mathrm{NS}^{\ddagger}$ \\
\hline Median & 2.0 & 2.0 & $\mathrm{NS}^{\S}$ \\
\hline Range & $1-20$ & $1-15$ & \multirow{3}{*}{$\mathrm{NS}^{\S}$} \\
\hline Single, No. (\%) & $20(30.3)$ & $21(27.3)$ & \\
\hline Multiple, No. (\%) & $46(69.7)$ & $56(72.7)$ & \\
\hline \multicolumn{4}{|l|}{ Education (years) } \\
\hline Mean \pm SD & $10.6 \pm 2.8$ & $11.9 \pm 3.8$ & $\mathrm{NS}^{\ddagger}$ \\
\hline Median & 10.5 & 12.0 & $0.011^{\S}$ \\
\hline$\leq 9$, No. $(\%)$ & $33(50.0)$ & $30(39.0)$ & \multirow{2}{*}{$\mathrm{NS}^{\star}$} \\
\hline$>9$, No. $(\%)$ & $33(50.0)$ & $47(61.0)$ & \\
\hline \multicolumn{4}{|l|}{ Stable partner relationship } \\
\hline Yes, No. (\%) & $36(54.5)$ & $57(74.0)$ & \multirow{2}{*}{$0.015^{\pi}$} \\
\hline No, No. (\%) & $30(45.5)$ & $20(26.0)$ & \\
\hline \multicolumn{4}{|l|}{ Occupation } \\
\hline Unpaidworker, No. (\%) & $56(84.8)$ & $59(76 . .6)$ & \multirow{2}{*}{$\mathrm{NS}^{\pi}$} \\
\hline Wageworker, No. (\%) & $10(15.2)$ & $18(23.4)$ & \\
\hline
\end{tabular}

'Significance value set al $\mathrm{p}<0.05$; NS, Not significant. "Mann-Whitney U test for independent samples comparing the mean values of continuous variables. ${ }^{\S}$ Median Test for Independent Samples. "Square Chi Test and/or Fisher's Exact Test comparing proportions of patients with a given variable. 
Table 2. Comparison of socio-demographic features among HPV-infected women.

\begin{tabular}{|c|c|c|c|}
\hline \multirow{2}{*}{ Variable } & \multicolumn{3}{|c|}{ Type of HPV infection } \\
\hline & Single genotype $(n=30)$ & Multiple genotype $(n=36)$ & p value ${ }^{\dagger}$ \\
\hline \multicolumn{4}{|l|}{ Age (years) } \\
\hline Mean \pm SD (Standard Deviation) & $28.6 \pm 9.0$ & $33.7 \pm 10.1$ & $\mathrm{NS}^{\ddagger}$ \\
\hline Median & 26.5 & 26.5 & $\mathrm{NS}^{\S}$ \\
\hline$\leq 21$, No. $(\%)$ & $6(20.0)$ & $10(27.8)$ & $\mathrm{NS}^{\pi}$ \\
\hline$>21$, No. $(\%)$ & $24(80.0)$ & $26(72.2)$ & \\
\hline \multicolumn{4}{|l|}{ Age at first sexual Intercourse (years) } \\
\hline Mean \pm SD & $19.1 \pm 3.8$ & $19.3 \pm 5.3$ & $\mathrm{NS}^{*}$ \\
\hline Median & 18.0 & 17.0 & $\mathrm{NS}^{\S}$ \\
\hline$\leq 16$, No. $(\%)$ & $8(26.7)$ & $15(41.7)$ & $\mathrm{NS}^{\pi}$ \\
\hline$>16$, No. $(\%)$ & $43(65.2)$ & $60(77.9)$ & \\
\hline \multicolumn{4}{|l|}{ Number of sex Partners } \\
\hline Mean \pm SD & $2.9 \pm 2.7$ & $4.0 \pm 5.0$ & $\mathrm{NS}^{\ddagger}$ \\
\hline Median & 2.0 & 2.0 & $\mathrm{NS}^{\S}$ \\
\hline Range & $1-6$ & $1-20$ & \\
\hline Single, No. (\%) & $9(30.0)$ & $11(30.6)$ & $\mathrm{NS}^{\S}$ \\
\hline Multiple, No. (\%) & $21(70.0)$ & $25(69.4)$ & \\
\hline \multicolumn{4}{|l|}{ Education (years) } \\
\hline Mean \pm SD & $10.5 \pm 2.9$ & $10.8 \pm 2.8$ & $\mathrm{NS}^{\ddagger}$ \\
\hline Median & 9.0 & 12 & $\mathrm{NS}^{\ddagger}$ \\
\hline$\leq 9$, No. $(\%)$ & $17(56.7)$ & $16(44.4)$ & $\mathrm{NS}^{*}$ \\
\hline$>9$, No. $(\%)$ & $13(43.3)$ & $20(55.6)$ & \\
\hline \multicolumn{4}{|l|}{ Stable partner relationship } \\
\hline Yes, No. (\%) & $16(53.3)$ & $20(55.6)$ & $0.015^{\pi}$ \\
\hline No, No. (\%) & $14(46.7)$ & $16(44.4)$ & \\
\hline \multicolumn{4}{|l|}{ Occupation } \\
\hline Unpaidworker, No. (\%) & $25(83.3)$ & $31(86.1)$ & $\mathrm{NS}^{\pi}$ \\
\hline Wageworker, No. (\%) & $5(16.7)$ & $5(13.9)$ & \\
\hline
\end{tabular}

†Significance value set al $\mathrm{p}<0.05$; NS, Not significant. "Mann-Whitney U test for independent samples comparing the mean values of continuous variables. ${ }^{\S}$ Median Test for Independent Samples. "Square Chi Test and/or Fisher's Exact Test comparing proportions of patients with a given variable. 
(a)

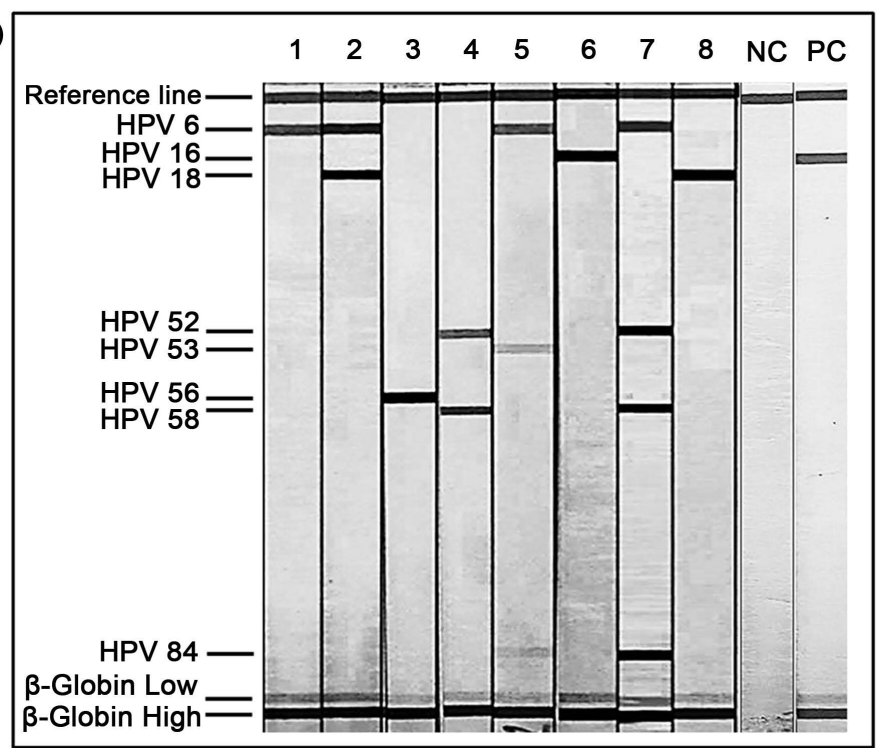

(b)

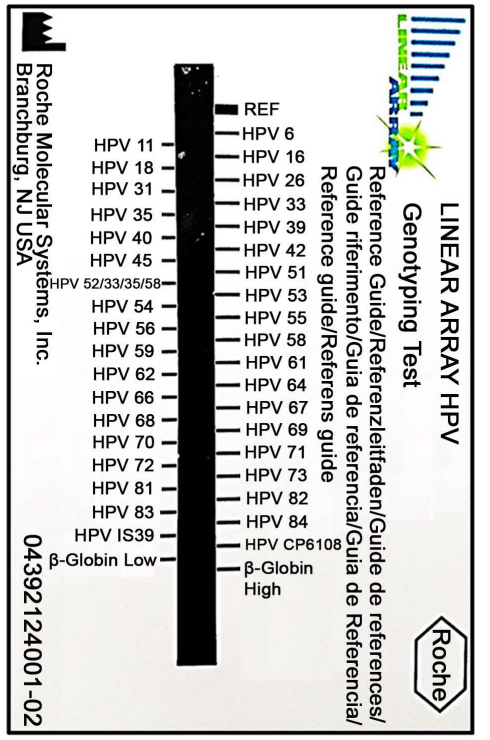

Line 1: HPV6; Line 2: HPV6, 18; Line 3: HPV56; Line 4: HPV52, 58; Line 5: HPV6, 53, 84;

Line 6: HPV16; Line 7: HPV6, 52, 58, 84; Line 8: HPV18; Line 9: C(-), Line: 10: C(+/HPV16).

Figure 2. Selected profile of genotyping results.

Table 3. Single- and multiple-genotype HPV infections among the study group.

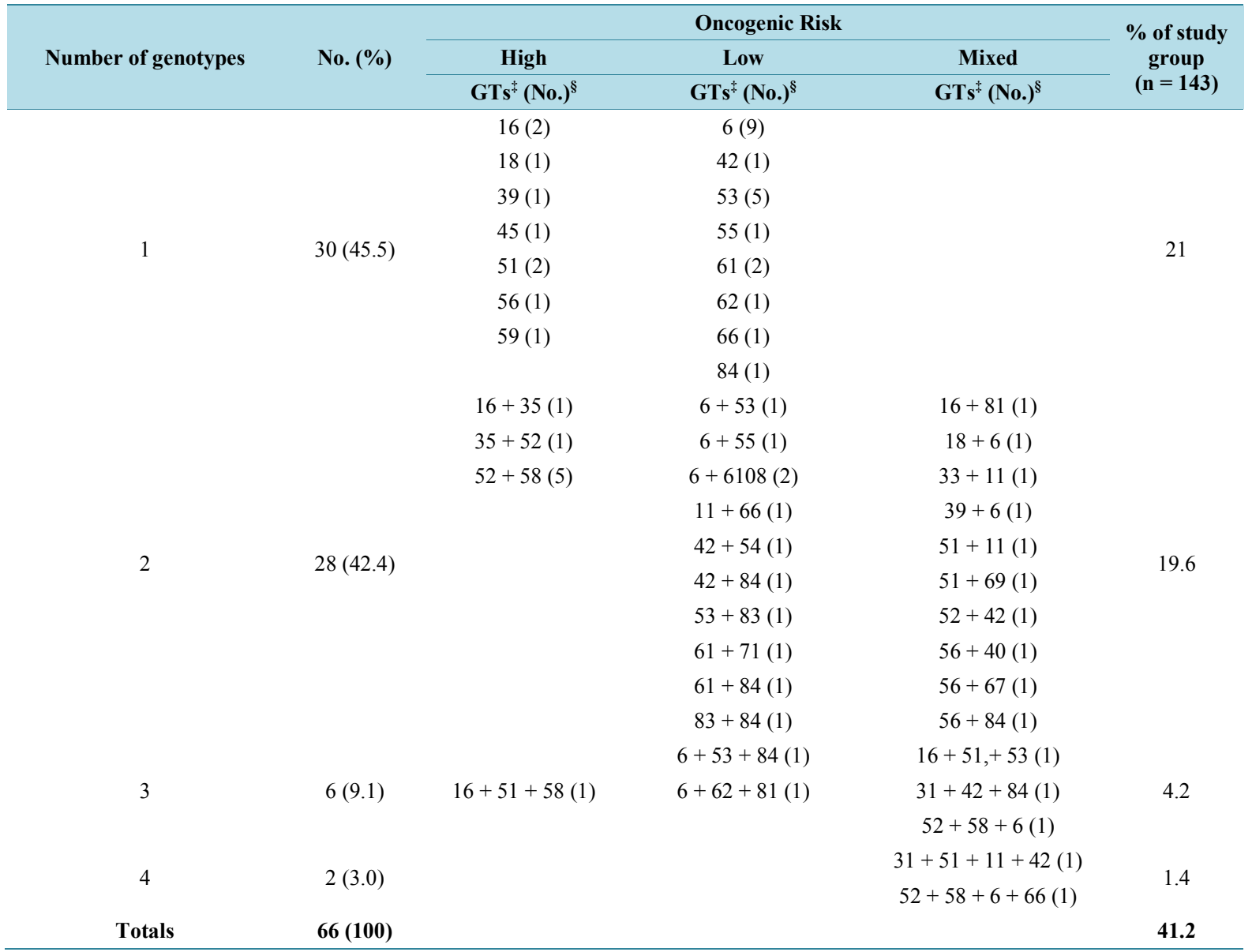

†Per single patient. ${ }^{\ddagger} \mathrm{HPV}$ genotypes. ${ }^{\S}$ Numbers within parenthesis indicate frequency of cases. 
hand, there is an ongoing openness in sexual practices among teenagers and young adults, who by the way are not afraid anymore of HIV/AIDS or other sexually transmitted infections, which in turn increases the likelihood for acquisition of HPV [16] [17]. Therefore it appears that such increase in cases of HPV-associated cervical cancer is the result of the concerted occurrence of the above mentioned issues.

In this study less than $50 \%$ of the women were infected with one or more HPV genotypes, which were heterogeneously distributed irrespective of their oncogenic risk. Our results are comparable with those from other studies with Mexican women [11] [18] [19]. In contrast, a meta-analysis about worldwide HPV detection among women with normal cytological findings, revealed an estimated frequency for Central America (including Mexico) of around $20 \%$, while estimated frequencies for worldwide and developing region were $7.2 \%$ and $14.3 \%$, respectively [20].

Data presented here revealed that HPV-infected women were significantly younger than those of the uninfected group, in agreement with previous reports [2] [18] [20] [21]. In contrast with results from other study with Mexican women [12], we do not found significant association between HPV infection and the number of sex partners, even though women infected with multiple genotypes had more sex partners than those infected by a single genotype, though this was not statistically significant. Lower level of education, short-term or null partner relationships and unpaid work were the predominant socio-demographic issues among HPV-infected women. Along with low income, those variables are highly associated with acquisition of HPV infection and/or cancer development [14] [18] [22] [23].

In this work, the relatively uncommon HPV genotypes in the cervix, HPV6, 52, 53, 58, 51 and 84, were detected at the highest frequencies (ranging from 17\% to 6.3\%). The main oncogenic genotypes, HPV16 and HPV18, were detected in frequencies lower than expected (5.4\% and 1.8\%, respectively). In contrast, higher frequencies of genotypes HPV16, 18 and 58 were reported among women from the southern coastal regions of Mexico, (14.6\%, 8.2\% and 7.9\%, respectively), whereas low-risk genotypes HPV 11 and 53 were found in frequencies below 6.8\% [11]. In a survey carried out among 1340 women of the South Central region of Mexico, whose cytological findings were normal, the high-risk genotypes HPV 16, 53, 31 and 18 were the most common, but their individual frequencies were lesser or equal to $1.7 \%$ [12].

The above mentioned studies used two different experimental approaches, one used universal PCR coupled to direct sequencing and the other used a reverse-line blot assay for up to 27 genotypes, which partially explain the differences between these and our study. A meta-analysis study showed that genotypes HPV16, 18, 31, 52, and 58 are consistently found among the 10 most common types across world regions, among women with normal cytological findings [18].

On the contrary, when groups of Mexican women presenting LSIL, HSIL or cervical cancer were analyzed, frequencies of HPV infection increased from $42 \%$ to $95 \%$, irrespective of the lesion type [19], although individual high-risk genotype frequencies were variable between studies. This confirms that there is a high correlation between presence of oncogenic HPV genotypes and different cervical lesions [2] [4]. In our study women had no evidence of cervical lesions and this partially explains the differing frequencies of high-risk genotypes.

Despite there are evident coincidences in the HPV genotypes identified in several studies, the use of different experimental approaches hampers appropriate comparisons. This confirms the need to uniform diagnostic approaches with the best molecular assay available, this should include identification of the maximum number possible of circulating HPV genotypes, without restricting detection to high-risk ones [6]-[9].

Nearly $60 \%$ of all HPV-infected patients in our study had multiple infections, with up to 4 genotypes, generally high- and low-risk types; this finding is in agreement with other studies employing the same molecular assay [6] [8] [24] [25]. Even though the presence of low-risk HPV genotypes within genital warts and tissue samples from cervical cancer has been demonstrated [2] [4] [12], there is a pervasive notion among clinicians that infection with low-risk HPV genotypes will not trigger malignant transformation, thus they neglect this finding as a threat for carcinogenesis [26]. The likelihood that those viruses with varying oncogenic potential can compete or act synergistically is rather high [4] [26] [27]. Moreover it is possible that simultaneous presence of 2 or more HPV genotypes can render a given patient more susceptible to develop cervical lesions than those who have a single-genotype infection.

Therefore, we strongly suggest mid- to long-term follow up for women presenting high- and low-risk genotypes, in order to detect and prevent further complications. Additionally, the varying geographical distribution of HPV types, also with diverse oncogenic potential [2] [28]-[30], suggest the importance of population-based studies to assess the influence of local genotypes prevalence on vaccine efficacy for the prevention of cervical cancer.

The relative high frequency of multiple-genotype infection among the women in our study could be sugges- 
tive of either persistence of some genotypes and subsequent acquisition of other genotypes (through risky sexual practices), or increased age-related host susceptibility [26].

In the light of the frequent multiple HPV infections detected in this study, some reports have suggested an association between multiple-genotype HPV infection and presence of cervical intraepithelial neoplasia and/or cervical cancer [27]. Accordingly, identification of both high- and low-risk HPV genotypes should be performed routinely, since an important proportion of cytology examinations will not show abnormal findings [26].

\section{Conclusion}

The use of a test able to detect/type up to 37 HPV genotypes, unrestricted to high-risk genotypes, allowed the identification of a relevant frequency of multiple HPV infections among a group of Mexican women without cervical abnormalities. Whether co-infections with low-risk HPV genotypes, or with high- and low-risk genotypes, may progress to pre-malignant or malignant transformation remains to be determined.

\section{Conflicts of Interest}

The authors have no conflicts of interest to declare.

\section{Funding}

Grant support: 2122250-077261. This study was sponsored by the National Institute of Perinatology, México City, México. Graciela Castro-Escarpulli and Silvia Giono-Cerezo received support from Estímulos al Desempeño en Investigación and Comisión y Fomento de Actividades Académicas (Instituto Politécnico Nacional) and Sistema Nacional de Investigadores (SNI, CONACyT).

\section{Ethical Approval}

Research was conducted according to ethical principles, and was approved by the Institutional Research and Ethics Committee (Protocol no. 212250-22761) of National Institute of Perinatology, México City, México.

\section{References}

[1] de Villers, E.M., Fauquet, C., Broker, T.R., et al. (2004) Classification of Papillomaviruses. Virology, 324, $17-27$. http://dx.doi.org/10.1016/j.virol.2004.03.033

[2] Chauhan, S.C., Jaggi, M., Bell, M.C., et al. (2009) Epidemiology of Human Papilloma Virus (HPV) in Cervical Mucosa. In: Verma, M., Ed., Methods in Molecular Biology-Cancer Epidemiology, Humana Press, Totowa, 438-455. http://dx.doi.org/10.1007/978-1-59745-416-2_22

[3] Carter, J.R., Ding, Z. and Rose, B.R. (2011) HPV Infection and Cervical Disease: A Review. Australian New Zealand Journal Obstetrics Gynaecology, 5, 103-108. http://dx.doi.org/10.1111/j.1479-828X.2010.01269.x

[4] de Freitas, A.C., Gurgel, A.P., Chagas, B.S., et al. (2012) Susceptibility to Cervical Cancer: An Overview. Gynecologic Oncology, 126, 304-311. http://dx.doi.org/10.1016/j.ygyno.2012.03.047

[5] Muñoz, N., Bosch, F.X., de Sanjosé, S., et al. (2003) Epidemiologic Classification of Human Papillomavirus Types Associated with Cervical Cancer. New England Journal Medicine, 348, 518-527. http://dx.doi.org/10.1056/NEJMoa021641

[6] Choi, Y.J. and Park, J.S. (2016) Clinical Significance of Human Papillomavirus Genotyping. Journal of Gynecologic Oncology, 27, e21. http://dx.doi.org/10.3802/jgo.2016.27.e21

[7] Gutierrez-Xicotencatl, L., Plett-Torres, T., Madrid-Gonzalez, C.L., et al. (2009) Molecular Diagnosis of Human Papillomaviruses in the Development of Cervical Cancer. Salud Pública de México, 51, S479-S488. http://dx.doi.org/10.1590/S0036-36342009000900014

[8] Sandri, M.T., Riggio, D., Salvatici, M., et al. (2009) Typing of Human Papillomavirus in Women with Cervical Lesions: Prevalence and Distribution of Different Genotypes. Journal of Medical Virology, 81, 271-277. http://dx.doi.org/10.1002/jmv.21382

[9] Huh, W.K., Ault, K.A., Chelmow, D., et al. (2015) Use of Primary High-Risk Human Papillomavirus Testing for Cervical Cancer Screening: Interim Clinical Guidance. GynecologicOncology, 136, 178-182. http://dx.doi.org/10.1016/j.ygyno.2014.12.022

[10] National Institute of Perinatology (2013) Organization Manual of the Medical Direction. Retrieved: 22 April 2016. 
http://www.inper.mx/descargas/pdf/MOrgDirMed.pdf

[11] Orozco-Colín, A., Carrillo-García, A., Méndez-Tenorio, A., et al. (2010) Geographical Variation in Human Papillomavirus Prevalence in Mexican Women with Normal Cytology. International Journal of Infectious Disease, 14, 10821087. http://dx.doi.org/10.1016/j.ijid.2010.07.007

[12] Lazcano-Ponce, E., Herrero, R., Mu-oz, N., et al. (2001) Epidemiology of HPV Infection among Mexican Women with Normal Cervical Cytology. International Journal of Cancer, 91, 412-420. http://dx.doi.org/10.1002/1097-0215(20010201)91:3<412::AID-IJC1071>3.0.CO;2-M

[13] Ting, J., Kruzikas, D.T. and Smith, J.S. (2010) A Global Review of Age-Specific and Overall Prevalence of Cervical Lesions. International Journal of Gynecological Cancer, 20, 1244-1249. http://dx.doi.org/10.1111/IGC.0b013e3181f16c5f

[14] Ochoa Carrillo, F.J., Guarneros de Regil, B. and Velasco Jiménez, Ma.T. (2015) Human Papillomavirus Infection in Women and Its Prevention. Gaceta Mexicana de Oncología, 4, 157-163. http://dx.doi.org/10.1016/j.gamo.2015.08.002

[15] Forouzanfar, M.H., Foreman, K.J., Delossantos, A.M., et al. (2011) Breast and Cervical Cancer in 187 Countries between 1980 and 2010: A Systematic Analysis. The Lancet, 378, 1461-1484. http://dx.doi.org/10.1016/S0140-6736(11)61351-2

[16] Bearinger, L.H., Sieving, R.E., Ferguson, J., et al. (2007) Global Perspectives on the Sexual and Reproductive Health of Adolescents: Patterns, Prevention, and Potential. The Lancet, 369, 1220-1231. http://dx.doi.org/10.1016/S0140-6736(07)60367-5

[17] Hajizade-Valokolaee, M., Yazdani-Khermandichali, F., Shahhosseini, Z. and Hamzehgardeshi, Z. (2016) Adolescents' Sexual and Reproductive Health: An Ecological Perspective. International Journal of Adolescent Medicine and Health, 20. http://www.degruyter.com/view/j/ijamh.ahead-of-print/ijamh-2015-0097/ijamh-2015-0097.xml

[18] Peralta-Rodríguez, R., Romero-Morelos, P., Villegas-Ruíz, V., et al. (2012) Prevalence of Human Papillomavirus in the Cervical Epithelium of Mexican Women: Meta-Analysis. Infectious Agents and Cancer, 7, 34. http://dx.doi.org/10.1186/1750-9378-7-34

[19] Romero-Pastrana, F. (2012) Detection and Typing of Human Papilloma Virus by Multiplex PCR With Type-Specific Primers. ISRN Microbiology, 2012, Article ID: 186915. http://dx.doi.org/10.5402/2012/186915

[20] Bruni, L., Díaz, M., Castellsagué, M., Ferrer, E., Bosch, X.F. and de Sanjosé, S. (2010) Cervical Human Papillomavirus Prevalence in 5 Continents: Meta-Analysis of 1 Million Women with Normal Cytological Findings. Journal of Infectious Diseases, 202, 1789-1799. http://dx.doi.org/10.1086/657321

[21] Farfan-Vargas, Y.A., Garcia-Robayo, D.A., Arias-Murillo, Y., et al. (2010) Genotiping Human Papillomavirus in Patients with Low-Grade Squamous Intraepithelial Lesion or Atipycal Squamous Cells of Uncertain Significance (ASC-US) in Bogotá, Colombia. Revista Colombiana de Ciencias Químico-Farmacéuticas, 39, 42-54.

[22] González-Losa, M.R., Rosado-López, I., Valdez-González, N. and Puerto-Solís, M. (2004) High Prevalence of Human Papillomavirus Type 58 in Mexican Colposcopy Patients. Journal of Clinical Virology, 29, 202-205.

[23] López-Revilla, R., Martínez-Contreras, L.A. and Sánchez-Garza, M. (2008) Prevalence of High-Risk Human Papillomavirus Types in Mexican Women with Cervical Intraepithelial Neoplasia and Invasive Carcinoma. Infectious Agents and Cancer, 3, 3. http://dx.doi.org/10.1186/1750-9378-3-3

[24] Gargiulo, F., De Francesco, M.A., Schreiber, C., et al. (2007) Prevalence and Distribution of Single and Multiple HPV Infections in Cytologically Abnormal Cervical Samples from Italian Women. Virus Research, 125, 176-182. http://dx.doi.org/10.1016/j.virusres.2006.12.017

[25] Venturoli, S., Ambretti, S., Cricca, M., et al. (2008) Correlation of High-Risk Papilloma Virus Genotypes Persistence and Risk of Residual or Recurrent Cervical Disease after Surgical Treatment. Journal of Medical Virology, 80, 14341440. http://dx.doi.org/10.1002/jmv.21198

[26] Mejlhede, N., Pedersen, B.V., Frisch, M., et al. (2010) Multiple Human Papillomavirus Types in Cervical Infections: Competition or Synergy? APMIS, 118, 346-352. http://dx.doi.org/10.1111/j.1600-0463.2010.2602.x

[27] Soto-De Leon, S., Camargo, M., Sanchez, R., et al. (2011) Distribution Paterns of Infection with Multiple Types of Human Papillomaviruses and Their Association with Risk Factor. PLoS ONE, 6, e14705. http://dx.doi.org/10.1371/journal.pone.0014705

[28] Dursun, P., Senger, S.S., Arslan, H., et al. (2009) Human Papillomavirus (HPV) Prevalence and Types among Turkish Women at a Gynecology Outpatient Unit. BMC Infectious Diseases, 9, 191. http://dx.doi.org/10.1186/1471-2334-9-191

[29] Delgado, D., Marín, J.M. and De Diego, J. (2012) Human Papillomavirus (HPV) Genotype Distribution in Women with Abnormal Cervical Cytology in the Basque Country, Spain. Enfermedades Infecciosas y Microbiología Clínica, 30, 230-235. http://dx.doi.org/10.1016/j.eimc.2011.10.021

[30] Ursu, R.G., Onofriescu, M., Nemescu, D., et al. (2011) HPV Prevalence and Type Distribution in Women with or without Cervical Lesions in the Northeast Region of Romania. Virology Journal, 8, 558.

http://dx.doi.org/10.1186/1743-422X-8-558 